\title{
Association of promoter region polymorphisms of interleukin-10 gene with susceptibility to colorectal cancer: a systematic review and meta-analysis
}

\author{
Seyed Alireza MIRJALILI', Mansour MOGHIMI ${ }^{2}$, Kazem AGHILI ${ }^{3}$, Mohammadali JAFARI ${ }^{4}$, \\ Seyed Mojtaba ABOLBAGHAEI ${ }^{5}$, Hossein NEAMATZADEH ${ }^{1}$, Mahta MAZAHERI ${ }^{1}$ and Masoud ZARE-SHEHNEH $^{1}$
}

\begin{abstract}
Background - Several epidemiological studies have investigated the association of promoter region polymorphisms of Interleukin-10 (IL-10) gene with colorectal cancer (CRC), while the conclusion is still conflicting and inconclusive. Objective - We conducted this meta-analysis to evaluate the association of promoter region polymorphisms of IL-10 with CRC. Methods - Eligible articles were identified by a search of several bibliographic databases for the period up to March 15, 2018. The strength of the association was measured by odd ratios with 95\% confidence intervals. Results A total of 28 case-control studies with 5,647 CRC cases and 6,908 controls were selected, including 14 studies for IL-10 -1082A > G (rs1800896) polymorphism (2,702 cases and 3,649 controls), eleven studies for -592C $>\mathrm{A}$ (rs1800872) polymorphism (3,259 cases and 4,992 controls), and three studies for $-819 \mathrm{~T}>\mathrm{C}$ (rs1800871) polymorphism (477 cases and 544 controls). By pooling all eligible studies, we found that the IL-10 $-1082 \mathrm{~A}>\mathrm{G}$ and $-592 \mathrm{C}>\mathrm{A}$ polymorphisms were not associated with increased CRC risk in overall population. However, there was significant associations between the IL-10 -819T >C polymorphism and CRC susceptibility under the allele model (A vs G: OR=1.278, 95\% CI 1.043-1.566, $P=0.018$ ) and the recessive model (AA vs AG+GG: OR=1.709, 95\% CI 1.026-2.845, $P=0.039$ ). Conclusion - In this meta-analysis we found that IL-10 $-819 \mathrm{~T}>\mathrm{C}$ polymorphism was associated with significantly increased risk of CRC; while the IL-10 -1082A $>$ G and $-592 \mathrm{C}>\mathrm{A}$ polymorphisms were not associated with CRC risk. The IL-10 -819T $>$ C polymorphism may be important as suspected predictive factor of CRC occurrence.
\end{abstract}

HEADINGS - Interleukin-10. Colorectal neoplasms. Genetic polymorphism. Meta-analysis.

\section{INTRODUCTION}

Colorectal cancer (CRC) ranks among the three most common cancers in terms of both cancer incidence and cancer-related deaths worldwide ${ }^{(1-4)}$. CRC is the cancer of the colon and the rectum and approximately two thirds are located in the colon. Differences in the $\mathrm{CRC}$ death rates relate to differences in socioeconomic factors, diet, population life span, genetic factors, and to the quality of medical care available ${ }^{(5,6)}$. The most common risk factors for to $\mathrm{CRC}$ include age, the presence of polyps, inflammatory bowel disease, lifestyle, genetic background and family medical history ${ }^{(7)}$. Life style relating factors such as obesity, physical inactivity, poor diet, cigarette smoking and heavy alcohol consumption account for approximately $80 \%$ of all colorectal cancer cases ${ }^{(8)}$. The sequence of genetic alterations in CRC development is well documented ${ }^{(9)}$. Genetic conditions such as familial adenomatous polyposis (FAP), Lynch syndrome (HNPCC; hereditary nonpolyposis colorectal cancer) and Gardner's syndrome (considered a subtype of FAP) are genetic risk factors ${ }^{(10)}$, which accounts for $10 \%$ of all colorectal cancer cases ${ }^{(11)}$.

Several cytokines that modulate the immunologic response have been implicated in the development of cancer ${ }^{(12)}$. Interleukin-10 (IL-10) is a multifunctional cytokine involved in both innate and adaptive immune response, and a wealth of evidence supports its regulatory role in carcinogenesis and tumor growth ${ }^{(13,14)}$. In addition, increased circulating IL10 has been shown in patients diagnosed with different malignancies, such as hepatocellular carcinoma, autoimmune cancers, and leukemia. The IL10 gene (Gene ID: 3586) has been mapped to human chromosome 1q31$\mathrm{q} 32$, spans $5.2 \mathrm{~kb}$ and contains five exons ${ }^{(14)}$. Many SNPs in the promoter and coding region of IL-10 gene were shown to be associated with cancer risk, and also, studies have showed that the genetic variants played important roles in the transcription and protein expression $^{(15)}$.

It is well known that IL-10 gene production can be influenced by the SNPs located within the promoter regions of the gene ${ }^{(15,16)}$. The IL-10 promoter is highly polymorphic and three single nucleotide polymorphisms (SNPs) have been confirmed in the promoter region of IL-10 including IL-10 -1082A > G (rs1800896), -592C > A (rs1800872) and -819T >C (rs1800871). In recent decade, accumulating evidence has supported the hypothesis that the promoter region of IL-10 polymorphisms correlates with genetic susceptibility of $\mathrm{CRC}^{(16,17)}$. However, the results from the studies were often inconsistent and inconclusive. This inconsistency may derive from a number of issues, including limited sample size of single

Declared conflict of interest of all authors: none

Disclosure of funding: no funding received

${ }^{1}$ Shahid Sadoughi University of Medical Sciences, Department of Medical Genetics, Yazd, Iran. ${ }^{2}$ Shahid Sadoughi University of Medical Sciences, Department of Pathology, Yazd, Iran. ${ }^{3}$ Shahid Sadoughi University of Medical Sciences, Department of Radiology, Yazd, Iran. ${ }^{4}$ Shahid Sadoughi University of Medical Sciences, Department of Emergency Medicine, Yazd, Iran. ${ }^{5}$ Shahid Beheshti University of Medical Sciences, Department of Forensic Medicine, Tehran, Iran.

Corresponding author: Mansour Moghimi. Orcid: 0000-0002-4000-9953. E-mail: moghimim1350@gmail.com 
study, different characteristics among studies (such as ethnicity, pathological types, and sources of controls), false-positive errors, lack of power, and minor impacts of IL-10 gene polymorphisms on CRC susceptibility. Therefore, we performed a meta-analysis to comprehensively assess the association of promoter region polymorphisms of IL-10 with CRC risk.

\section{METHODS}

\section{Identification of eligible studies}

The present meta-analysis was conducted according to the Preferred Reporting Items for Systematic Reviews and Meta-analysis (PRISMA) guidelines. We carried out a search in the internet covering well-known biomedical databases such as PubMed, Excerpta Medica Database (EMBASE), Elsevier Science Direct, Cochrane Library, and Chinese Biomedical Literature Database (CBM) regarding the association of IL-10 polymorphisms with CRC risk up to March 15, 2018. The following keywords were used for searching: ("Interleukin- 10" OR "IL-10") AND ("colorectal cancer" OR "CRC" OR "colon cancer") AND ("promoter region" OR "promoter") AND ("polymorphism" OR "mutation" OR "genotype" OR "allele" OR "variation" OR "variant"). All searched studies were retrieved and the bibliographies were checked for other relevant publications. Review articles and bibliographies of other relevant studies identified were hand searched to find additional eligible studies. We also conducted a manual search of references of original or reviewed articles on this subject to identify additional studies. No language restrictions were applied. Abstracts, case reports and editorials were excluded.

\section{Inclusion criteria}

The following criteria were used for the literature selection: (1) evaluating the association between promoter region polymorphisms of IL-10 and CRC risk; (2) case-control or cohort studies comparing CRC cases with healthy or non-cancer controls; (3) the numbers of CRC case and healthy subjects for each genotype were reported or the relevant data was available, and adequate data was provided for calculating the pooled odds ratios (OR) with $95 \%$ confidence intervals (CI). Studies was excluded if they were the following: (1) case-only studies; (2) animal studies, abstracts, seminar posters, case reports, letters, or reviews; (3) incomplete data or no usable data were reported; (4) duplicated or studies containing overlapping data; (5) family-based design studies. After deliberate searching, we reviewed all papers in accordance with the criteria defined above for further analysis.

\section{Data extraction}

Information was carefully extracted from all eligible papers by two of the authors independently according to the inclusion criteria mentioned above. Data included the following: first author, publication year, country, cancer type, source of control, each genotype frequency of the case and control groups, genotype methods, and the Hardy-Weinberg equilibrium (HWE) value in the control group. Disagreement was resolved by discussion until consensus was reached. If these two authors could not reach a consensus, then a third author was consulted to resolve the dispute.

\section{Statistical analysis}

The strength of the association between the IL-10 polymorphisms and the risk of CRC was measured by odd ratios (ORs) with
$95 \%$ confidence intervals (CI). Z-test was carried out to evaluate the statistical significance of pooled ORs. The pooled ORs were performed for the allele model (B vs A), homozygote model (BB vs $\mathrm{AA})$, heterozygote model (BA vs $\mathrm{AA})$, dominant model (BB + $\mathrm{BA}$ vs $\mathrm{AA}$ ) and recessive model (BB vs $\mathrm{BA}+\mathrm{AA})$, respectively. The heterogeneity between studies was assessed with the chi-squared based Q-test. A significant $P$ value $(<0.10)$ was used to indicate heterogeneity among studies. Moreover, the $\mathrm{I}^{2}$ statistic to quantify the proportion of the total variation due to heterogeneity were used, according to the criteria from the Cochrane Handbook, which categorized it into unimportant $(0 \%-40 \%)$, moderate $(30 \%-60 \%)$, substantial (50\%-90\%) and considerable (75\%-100\%). When the effects were assumed to be homogenous, the fixed-effects model was used (Mantel-Haenszel method) ${ }^{(18)}$. If obvious heterogeneity was present, the random effects model was used (DerSimonian-Laird method $)^{(19)}$. Stratification and meta-regression analyses were used to detect the potential heterogeneity among studies. In case-control studies, Hardy-Weinberg equilibrium (HWE) was tested using an online program (http://ihg2.helmholtz-muenchen.de/cgi-bin/hw/ hwa1.pl) to evaluate the study quality of genotype data, and $P<0.05$ was considered statistically significant. A high-quality study was said that its control group was in HWE. Sensitivity analysis by sequentially omitting the single studies and recounting the pooled ORs and $95 \%$ confidence intervals (CIs) was performed to estimate the effect of individual studies on overall risk of CRC. The funnel plot was utilized to test the publication bias and Egger's test (linear regression analysis) was used to check the symmetry of funnel plots $^{(20,21)}$. The statistical analysis for the current meta-analysis study was performed by using the comprehensive meta-analysis (CMA) version 2.0 software (Biostat, USA). All $P$-values in the meta-analysis were two-sided, and statistical significance was considered when the $P$-value was less than 0.05 .

\section{RESULTS}

The initial search of online databases yielded 253 relevant articles, and an additional 4 articles were identified through manually search. A total of 157 articles were excluded after reading the title or abstract because of obvious irrelevance to our criteria, lack of data for calculation and duplication. Finally, a total of 28 case-control studies in 17 publications ${ }^{(22-38)}$ with 5,647 CRC cases and 6,908 controls were selected for the current meta-analysis, including 14 studies $^{(22-35)}$ for IL-10 -1082A > G (rs1800896) polymorphism (2,702 cases and 3,649 controls), eleven case-control studies $^{(22,23,25,26,28,29,32,34,36-38)}$ for $-592 \mathrm{C}>\mathrm{A}$ (rs 1800872) polymorphism (3,259 cases and 4,992 controls), and three case-control studies $^{(24,25,28)}$ for $-819 \mathrm{~T}>\mathrm{C}$ (rs1800871) polymorphism (477 cases and 544 controls). All of these 28 case-control studies provided sufficient data to calculate the possible relationship between the three polymorphisms of the IL-10 gene and CRC risk. The baseline characteristics of the case-control studies are shown in TABLE 1. Two ethnicities were addressed: 24 studies focused on Caucasian populations and four on Asian populations. The countries of these studies included Scotland, Italy, USA, Spain, Romania, Brazil, Canada, China, India, Korea, Egypt, and Turkey. Three genotyping methods were applied in the present case-control studies such as TaqMan, ARMS-PCR, Sequencing, AS-PCR, MassARRAY, PCR-RFLP, and KASP assay. The distribution of genotypes in the controls was consistent with the HWE for all selected studies, except for three case-control studies for IL-10 -1082A $>G^{(24,28,33)}$. 
TABLE 1. Characteristics of studies included in the meta-analysis.

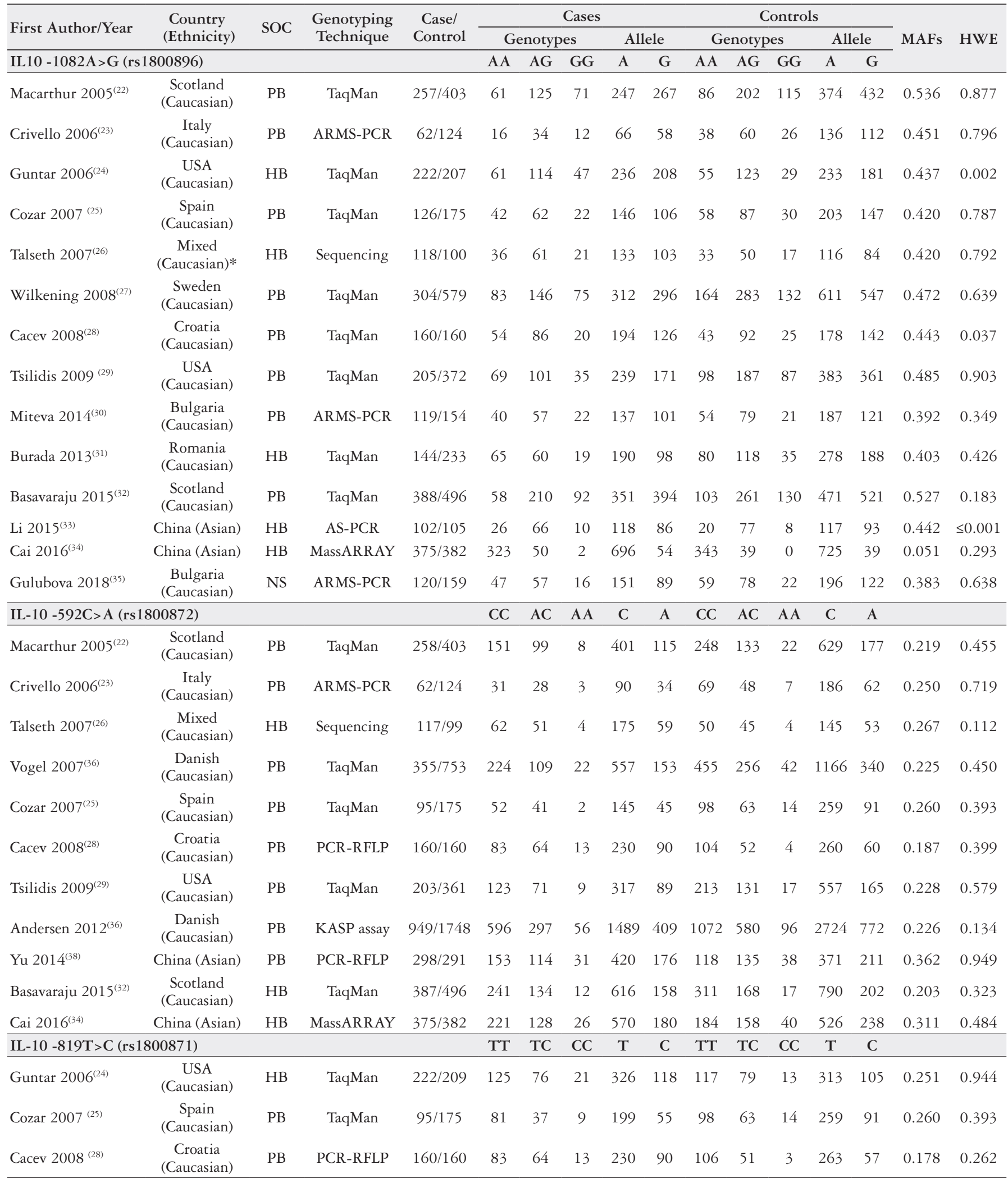

SOC: source of control, PB: Population based; HB: hospital based; NA: not available; PCR: Polymerase chain reaction; ASPCR: Allele-specific PCR; RFLP: restriction fragment length polymorphism; MAF: minor allele frequency; HWE: Hardy-Weinberg equilibrium. * Australia and Poland. 


\section{Quantitative synthesis}

The evaluation of the associations of IL-10 $-1082 \mathrm{~A}>\mathrm{G}$, $-592 \mathrm{C}>\mathrm{A}$ and $-819 \mathrm{~T}>\mathrm{C}$ polymorphisms with CRC risk are presented in TABLE 2. The results showed that no association of IL-10 polymorphism was observed with the risk of CRC in five genetic models, i.e., allele (A vs G: OR $=0.9623,95 \%$ CI 0.893-1.038, $P=0.318$, FIGURE 1.A), homozygote (AA vs GG: $\mathrm{OR}=0.983,95 \%$ CI $0.836-1.155, P=0.835$ ), heterozygote (AC vs $\mathrm{GG}: \mathrm{OR}=0.953$, 95\% CI 0.843-1.078, $P=0.444$ ), dominant (AA+AG vs GG: $\mathrm{OR}=0.921,95 \% \mathrm{CI} 0.821-1.034, P=0.165)$ and recessive model (AA vs $\mathrm{AG}+\mathrm{GG}$ : $\mathrm{OR}=0.986,95 \% \mathrm{CI} 0.861-1.129, P=0.839$ ).
TABLE 2 listed the main results of the meta-analysis of IL-10 polymorphism and CRC risk. When all the eligible studies were pooled into the meta-analysis of IL-10 polymorphism, significantly increased risk of CRC was observed in all the five genetic comparison models, i.e., allele (A vs G: $\mathrm{OR}=1.497,95 \%$ CI 0.838-1.064, $P=0.349$ ), homozygote (AA vs GG: $\mathrm{OR}=2.153$, 95\% CI 0.705-1.047, $P=0.132$ ), heterozygote (AC vs GG: $\mathrm{OR}=1.494,95 \% \mathrm{CI} 0.826-1.094, P=0.481)$, dominant $(\mathrm{AA}+\mathrm{AG}$ vs GG: $\mathrm{OR}=1.584,95 \% \mathrm{CI} 0.693-1.145, P=0.368$, FIGURE 1.B) and recessive (AA vs AG+GG: $\mathrm{OR}=1.753,95 \% \mathrm{CI}$ 0.747-1.099, $P=0.319)$.

TABLE 2. Results of the association of IL-10 promoter region polymorphisms with CRC risk.

\begin{tabular}{|c|c|c|c|c|c|c|c|c|c|c|}
\hline \multirow{2}{*}{ Subgroup } & \multirow{2}{*}{ Genetic Model } & \multirow{2}{*}{$\begin{array}{l}\text { Type of } \\
\text { Model }\end{array}$} & \multicolumn{2}{|c|}{ Heterogeneity } & \multicolumn{4}{|c|}{ Odds Ratio } & \multicolumn{2}{|c|}{ Publication Bias } \\
\hline & & & $\mathrm{I}^{2}(\%)$ & $P_{\mathrm{H}}$ & OR & $95 \% \mathrm{CI}$ & $Z_{\text {test }}$ & $P_{\mathrm{OR}}$ & $P_{\text {Beggs }}$ & $P_{\text {Eggers }}$ \\
\hline \multicolumn{11}{|c|}{ IL-10 -1082A>G (rs1800896) } \\
\hline & G vs $A$ & Fixed & 10.58 & 0.337 & 0.962 & $0.893-1.038$ & -0.999 & 0.318 & 0.228 & 0.422 \\
\hline & GG vs AA & Fixed & 3.88 & 0.408 & 0.983 & $0.836-1.155$ & -0.208 & 0.835 & 0.826 & 0.664 \\
\hline & GA vs $A A$ & Fixed & 16.60 & 0.272 & 0.953 & $0.843-1.078$ & -0.766 & 0.444 & 0.826 & 0.688 \\
\hline & $\mathrm{GG}+\mathrm{GA}$ vs $\mathrm{AA}$ & Fixed & 0.00 & 0.458 & 0.921 & $0.821-1.034$ & -1.387 & 0.165 & 0.324 & 0.826 \\
\hline & A vs $\mathrm{C}$ & Random & 53.69 & 0.017 & 0.945 & $0.838-1.064$ & -0.937 & 0.349 & 0.533 & 0.544 \\
\hline & AA vs CC & Fixed & 37.90 & 0.097 & 0.859 & $0.705-1.047$ & -1.507 & 0.132 & 1.000 & 0.863 \\
\hline & AC vs CC & Random & 45.87 & 0.047 & 0.951 & $0.826-1.094$ & -0.704 & 0.481 & 0.275 & 0.328 \\
\hline & $\mathrm{AA}+\mathrm{AC}$ vs $\mathrm{CC}$ & Random & 84.90 & $\leq 0.001$ & 0.891 & $0.693-1.145$ & -0.900 & 0.368 & 0.350 & 0.005 \\
\hline & $\mathrm{AA}$ vs $\mathrm{AC}+\mathrm{CC}$ & Fixed & 24.83 & 0.207 & 0.906 & $0.747-1.099$ & -0.997 & 0.319 & 0.436 & 0.625 \\
\hline & $\mathrm{CC}+\mathrm{CT}$ vs TT & Fixed & 52.19 & 0.123 & 1.253 & $0.974-1.611$ & 1.757 & 0.079 & 1.000 & 0.653 \\
\hline & $\mathrm{CC}$ vs $\mathrm{CT}+\mathrm{TT}$ & Fixed & 33.49 & 0.222 & 1.709 & $1.026-2.845$ & 2.060 & 0.039 & 1.000 & 0.411 \\
\hline
\end{tabular}

\section{A Study name}

$\begin{array}{lccccc} & \begin{array}{c}\text { Odds } \\ \text { ratio }\end{array} & \begin{array}{c}\text { Lower } \\ \text { limit }\end{array} & \begin{array}{c}\text { Upper } \\ \text { limit }\end{array} & \text { Z-Value } & \boldsymbol{P} \text {-Value } \\ \text { Macarthur 2005 } & 0.936 & 0.750 & 1.168 & -0.586 & 0.558 \\ \text { Crivello 2006 } & 1.067 & 0.692 & 1.644 & 0.294 & 0.768 \\ \text { Guntar 2006 } & 1.135 & 0.867 & 1.485 & 0.919 & 0.358 \\ \text { Cozar 2007 } & 1.003 & 0.722 & 1.392 & 0.016 & 0.988 \\ \text { Talseth 2007 } & 1.069 & 0.731 & 1.565 & 0.346 & 0.730 \\ \text { Wilkening 2008 } & 1.060 & 0.871 & 1.290 & 0.579 & 0.563 \\ \text { Cacev 2008 } & 0.814 & 0.594 & 1.115 & -1.281 & 0.200 \\ \text { Tsilidis 2009 } & 0.759 & 0.595 & 0.968 & -2.220 & 0.026 \\ \text { Miteva 2014 } & 1.139 & 0.808 & 1.607 & 0.743 & 0.457 \\ \text { Burada 2013 } & 0.763 & 0.562 & 1.036 & -1.735 & 0.083 \\ \text { Basavaraju 2015 } & 0.932 & 0.773 & 1.125 & -0.729 & 0.466 \\ \text { Li 2015 } & 0.917 & 0.621 & 1.353 & -0.437 & 0.662 \\ \text { Cai 2016 } & 1.442 & 0.943 & 2.206 & 1.690 & 0.091 \\ \text { Gulubova 2018 } & 0.947 & 0.670 & 1.338 & -0.309 & 0.757 \\ & 0.962 & 0.893 & 1.038 & -0.999 & 0.318\end{array}$

\section{Statistics for each study}

\begin{tabular}{l|}
0.558 \\
0.768 \\
0.358 \\
0.988 \\
0.730 \\
0.563 \\
0.200 \\
0.026 \\
0.457 \\
0.083 \\
0.466 \\
0.662 \\
0.091 \\
0.757
\end{tabular}

\section{Odds ratio and $95 \% \mathrm{Cl}$}

Relative weight

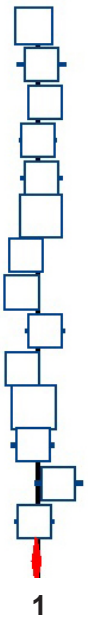

11.54

3.03

7.82

5.26

3.91

14.67

5.73

9.57

4.79

6.05

16.03

3.74

3.14

4.73

FIGURE 1.A. Forest plots for association of IL-10 -1082A $>G$ and -592C $>A$ polymorphisms with CRC risk. (A) $-1082 A>G$ under allele model $(G$ vs. A). 
B

Study name

$\begin{array}{lccccc} & \begin{array}{c}\text { Odds } \\ \text { ratio }\end{array} & \begin{array}{c}\text { Lower } \\ \text { limit }\end{array} & \begin{array}{c}\text { Upper } \\ \text { limit }\end{array} & \text { Z-Value } & \boldsymbol{P} \text {-Value } \\ \text { Macarthur 2005 } & 1.134 & 0.824 & 1.559 & 0.772 & 0.440 \\ \text { Crivello 2006 } & 1.255 & 0.681 & 2.311 & 0.727 & 0.467 \\ \text { Talseth 2007 } & 0.905 & 0.530 & 1.547 & -0.364 & 0.716 \\ \text { Vogel 2007 } & 0.893 & 0.688 & 1.159 & -0.852 & 0.394 \\ \text { Cozar 2007 } & 1.052 & 0.637 & 1.739 & 0.199 & 0.842 \\ \text { Cacev 2008 } & 1.723 & 1.100 & 2.700 & 2.374 & 0.018 \\ \text { Tsilidis 2009 } & 0.936 & 0.659 & 1.330 & -0.369 & 0.712 \\ \text { Andersen 2012 } & 0.468 & 0.398 & 0.551 & -9.174 & 0.000 \\ \text { Yu 2014 } & 0.646 & 0.467 & 0.896 & -2.622 & 0.009 \\ \text { Basavaraju 2015 } & 1.001 & 0.761 & 1.317 & 0.007 & 0.994 \\ \text { Cai 2016 } & 0.648 & 0.486 & 0.863 & -2.963 & 0.003 \\ & 0.891 & 0.693 & 1.145 & -0.900 & 0.368\end{array}$

Statistics for each study

\section{Odds ratio and $95 \% \mathrm{Cl}$}

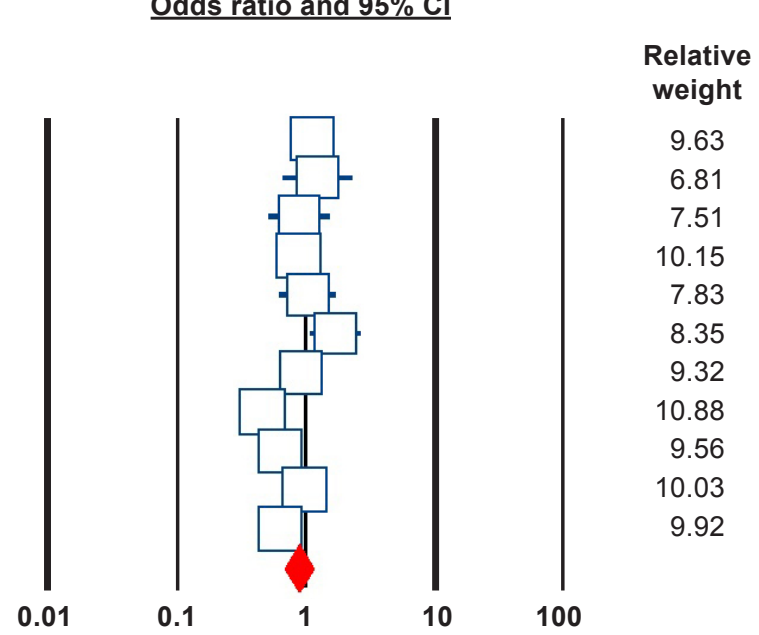

FIGURE 1.B. $-592 \mathrm{C}>\mathrm{A}$ under dominant model (AA+AC vs. CC).

TABLE 2 listed the main results of the meta-analysis of IL$10-819 \mathrm{~T}>\mathrm{C}$ (rs1800871) polymorphism and CRC risk. When all the eligible studies were pooled into the meta-analysis of IL-10 $-819 \mathrm{~T}>\mathrm{C}$ (rs1800871) polymorphism, significantly increased risk of $\mathrm{CRC}$ was observed in the two genetic models, i.e., allele (A vs $\mathrm{G}: \mathrm{OR}=1.278,95 \% \mathrm{CI} 1.043-1.566, P=0.018$ ) and recessive (AA vs $\mathrm{AG}+\mathrm{GG}$ : $\mathrm{OR}=1.709,95 \% \mathrm{CI} 1.026-2.845, P=0.039$ ).

The studies were further stratified on the basis of ethnicity, source of control, genotyping technique and HWE status. Subgroup analysis did not showed the IL-10 $-1082 \mathrm{~A}>\mathrm{G}$ and $-592 \mathrm{C}>\mathrm{A}$ polymorphisms significantly increased risk of $\mathrm{CRC}$ (data not showed).

\section{Heterogeneity and sensitivity analyses}

TABLE 2 summarizes the results of this meta-analysis for heterogeneity test. For IL-10 $-1082 \mathrm{~A}>\mathrm{G}$ polymorphism, there was no a significant heterogeneity in all five genetic models. Our meta-analysis showed little evidence of genetic heterogeneity in the homozygote model of IL-10 -819T $>$ C . We detected significant between-study heterogeneity in the three genetic models, i.e., allele, heterozygote and dominant for $-592 \mathrm{C}>\mathrm{A}$. One-way sensitivity analyses were performed by iteratively removing one study at a time to assess the stability of the meta-analysis results. The result showed that there was still no significant association of IL-10 -1082A $>$ G and $-819 \mathrm{~T}>\mathrm{C}$ polymorphisms with CRC. Significant between-study heterogeneity was still significant after removing one study under the genetic models (data not shown).

\section{Publication bias}

We performed Begg's test and Egger's test to assess the publication bias. As shown in the TABLE 2, no obvious publication bias was found according to the obtained $P$ values for all the genetic models for IL-10 $-1082 \mathrm{~A}>\mathrm{G}$ and $-819 \mathrm{~T}>\mathrm{C}$ polymorphisms. However, the results of Egger's regression test and relative asymmetry of funnel plot showed evidence of publication bias for IL-10 $-592 \mathrm{C}>$ A under the dominant model $\left(P_{\text {Beggs }}=0.350, P_{\text {Eggers }}=0.005\right.$,
FIGURE 2), suggesting that there was obvious publication bias in the genetic model. Therefore, we have performed the Duval and Tweedie nonparametric "trim and fill" method to adjust for publication bias. The "trim and fill" method did not change conclusion, indicating that our results were statistically robust.

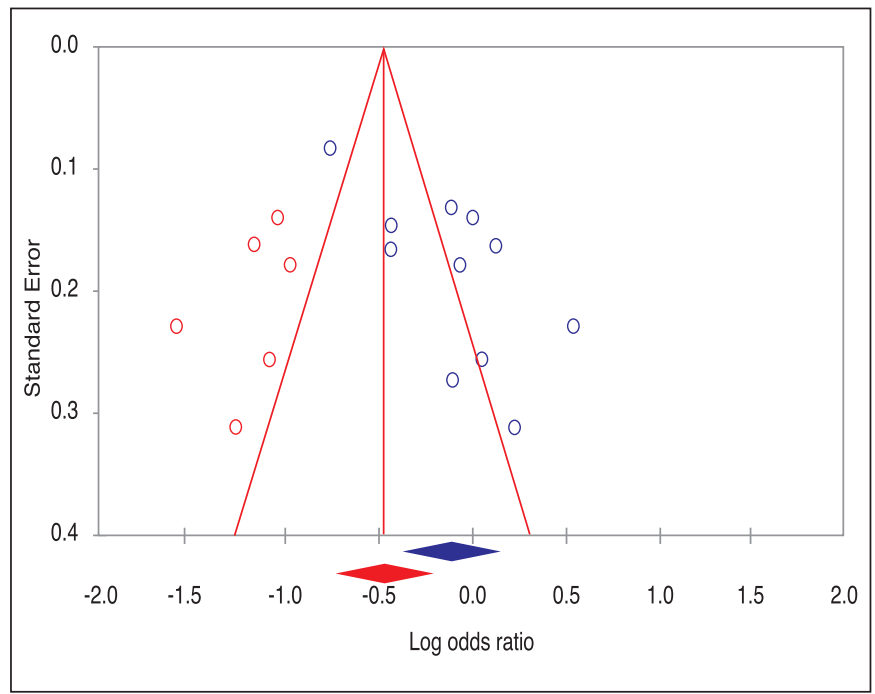

FIGURE 2. Begg's funnel plot of publication bias test before (blue) and after (red) trim-and-fill method for IL10 $-592 \mathrm{C}>\mathrm{A}$ polymorphism with $\mathrm{CRC}$ risk under dominant model ( $\mathrm{AA}+\mathrm{AC}$ vs. $\mathrm{CC})$.

\section{Minor Allele Frequencies (MAFs)}

The minor allele frequencies (MAFs) of the IL-10 polymorphisms are presented in TABLE 1 . The IL10 -1082G, $-592 \mathrm{~A}$ and $-819 \mathrm{C}$ allele frequencies in the overall populations were $29.35 \%$ (5.10\%-53.60\%), 27.45\% (18.70\%-36.20\%), and 21.9\% (17.80\%$26.0 \%$ ), respectively. 


\section{DISCUSSION}

To date, numerous molecular epidemiological studies have been conducted to evaluate the association between polymorphisms of IL-10 promoter polymorphisms and the risk of CRC, but results have remained conflicting. In this meta-analysis, we identified 28 eligible studies, including 5,647 CRC cases and 6,908 controls, and analyzed the association of IL-10 $-1082 \mathrm{~A}>\mathrm{G},-592 \mathrm{C}>\mathrm{A}$ and $-819 \mathrm{~T}>\mathrm{C}$ polymorphisms with susceptibility to $\mathrm{CRC}$. We found that the IL-10 $-1082 \mathrm{~A}>\mathrm{G}$ and $-592 \mathrm{C}>\mathrm{A}$ polymorphisms were not associated with CRC risk in overall population. We suggested that the IL-10 $-1082 \mathrm{~A}>\mathrm{G}$ and $-592 \mathrm{C}>\mathrm{A}$ polymorphisms could play a protective role in the development of CRC due to a higher incidence found in controls than in cases from the included studies in the meta-analysis.

Previously, association of the IL-10 polymorphisms with CRC risk has been investigated by two meta-analyses. In 2013, Yu et al. performed a comprehensive meta-analysis about IL-10 -819C $>$ T polymorphism and cancer susceptibility. They have found that the IL-10 -819C $>$ T polymorphism was not significantly associated with $\mathrm{CRC}$, breast cancer, lung cancer, hepatocellular carcinoma, prostate cancer, lymphoma, or melanoma ${ }^{(16)}$. Compared with Yu et al., we only focused on the association of IL-10 polymorphisms with CRC cancer, while $\mathrm{Yu}$ et al. analyzed a variety of human malignancies. In 2012, Zhang et al. performed a meta-analysis about IL-10 -1082 $\mathrm{A}>\mathrm{G}$ and $-592 \mathrm{C}>\mathrm{A}$ polymorphisms and $\mathrm{CRC}$ risk $^{(17)}$. Compared with $\mathrm{Yu}$ et al. and Zhang et al. studies, we have focused on the association of three promoter region polymorphisms with CRC. On the other hand, we also analyzed the association of IL-10 -819T $>C$ polymorphism with CRC risk. Additionally, we identified more eligible studies undertaken to assess the association IL-10 gene promoter polymorphisms and CRC risk.

To the best knowledge, this is the first comprehensive metaanalysis to assess the association of IL-10 -819T $>$ C polymorphism with CRC risk. The current meta-analysis, which included a total of three case-control studies with 477 cases and 544 controls, investigated the association of IL-10 -819T $>$ C polymorphism with CRC risk. We found that the IL-10 -819T >C polymorphism significantly increased risk of $\mathrm{CRC}$ in the two genetic models, i.e., allele (A vs G: $\mathrm{OR}=1.278,95 \%$ CI 1.043-1.566, $P=0.018$ ) and recessive (AA vs $\mathrm{AG}+\mathrm{GG}$ : $\mathrm{OR}=1.709,95 \% \mathrm{CI} 1.026-2.845$, $P=0.039$ ). However, a small number of eligible studies were enrolled for IL-10 -819T >C polymorphism, which may fail to provide enough statistical power to detect a possible or effect of IL-10 -819T>C polymorphism on CRC. Therefore, to achieve more precise correlation, future studies should take ethnic difference in to consideration. However, we suggests that the IL-10 $-819 \mathrm{~T}>\mathrm{C}$ polymorphism may be important as suspected predictive factor for CRC occurrence.

Between-study heterogeneity is a potential problem that might affect the interpretation of the results. thus, one of the most important goals of the meta-analysis is to identify the source of heterogeneity ${ }^{(39-42)}$. Through conducting meta-regression, we found that the heterogeneity could not be explained by ethnicity, source of control, genotyping methods and HWE status in the current meta-analysis. Therefore, we suggested that the heterogeneity may have resulted due to something more than these factors. It is known that the existence of publication bias can influence the conclusions of a meta-analysis. Therefore, the "trim and fill" methods have been developed to deal with publication bias. In the current metaanalysis, we have found possible publication bias between IL-10 $-592 \mathrm{C}>\mathrm{A}$ polymorphism and CRC risk under the dominant model $\left(P_{\text {Beggs }}=0.350, P_{\text {Eggers }}=0.005\right)$, adjusting for possible publication bias using the Duval and Tweedie nonparametric "trim and fill" method showed that the results did not adjust, indicating that the overall pooled results should be unbiased.

In interpreting the results, some cautions should be applied. First, there was limited number of eligible studies in the meta-analysis of the association between IL-10-819T $>$ C polymorphism and risk of CRC. The limited sample size in the meta-analysis may fail to provide enough statistical power to detect a possible or weak effect of IL-10 -819T >C polymorphism on CRC. Therefore, more studies with large sample are needed to give a more precise estimation of the association between IL-10 -819T >C polymorphism and risk of CRC. Second, the included studies involved in the meta-analysis were mainly Caucasian, so it is uncertain whether these results are generalizable to other populations. Moreover, the stratification by ethnicity had little or no information for other ethnicities, which may limited the strength of our results. Thus, strengthening the statistical power will require more data from different ethnicities. Third, although no significant publication bias was detected, we have included only published studies in this meta-analysis, and it is possible that some relevant published and unpublished studies in other languages might be missed, which also publication bias may occur. Fourth, our results were based on unadjusted estimates without adjustment for other risk factors such as age, gender, drinking consumption, environmental factors and other variables, while a more precise analysis should be conducted according to potentially confounding factors. Finally, lack of the original data of the included studies, the interaction of different susceptibility genes, gene-to-environment, and even different polymorphic loci of the same gene interactions due to the limited information of included studies.

In conclusion, this meta-analysis indicated that IL-10 $-1082 \mathrm{~A}>\mathrm{G}$ and $-592 \mathrm{C}>\mathrm{A}$ polymorphisms could play a protective role in the development of CRC. However, we found that there was a significant association between IL-10 -819T $>$ C polymorphism and CRC risk. The IL-10 -819T $>$ C polymorphism may be important as suspected predictive factor of CRC occurrence. More extensive studies with large sample sizes, gene-gene and gene-environment interactions are necessary to provide a more reliable estimation of these associations in overall and by ethnicity.

\section{Authors' contributions}

Mirjalili SA, Moghimi M and Neamatzadeh H conceived and research design. Abolbaghaei SM and Mazaheri M selected the articles and extracted the data. Aghili K, Jafari M and ZareShehneh M performed data analysis. The manuscript was drafted by Mirjalili SA and Neamatzadeh H. Moghimi M and Abolbaghaei SM critically reviewed the manuscript and discussed with the other co-authors. All the authors read and approved the final manuscript. 
Mirjalili SA, Moghimi M, Aghili K, Jafari M, Abolbaghaei SM, Neamatzadeh H, Mazaheri M, Zare-Shehneh M. Associação de polimorfismos da região do promotor do gene interleucina-10 com susceptibilidade ao câncer colorretal: uma revisão sistemática e meta-análise. Arq Gastroenterol. 2018,55(3):306-13.

RESUMO - Contexto - Vários estudos epidemiológicos têm investigado a associação de polimorfismo da região promotora do gene interleucina-10 (IL-10) com câncer colorretal (CRC), mas por enquanto a conclusão ainda é conflitante e inconclusiva. Objetivo - Foi realizada esta meta-análise para avaliar a associação de polimorfismo da região promotora do Il-10 com o câncer colorretal. Métodos - Os artigos elegíveis foram identificados por uma pesquisa de várias bases de dados bibliográficas para o período até 15 de março de 2018 . A força da associação foi medida por odds ratio (OR) com intervalos de 95\% de confiança (IC). Resultados - Um total de 28 estudos de casos-controles com 5.647 casos de câncer colorretal e 6.908 controles foram selecionados, incluindo 14 estudos para o polimorfismo de IL-10-1082A > G (rs1800896) (2.702 casos e 3.649 controles), 11 estudos para-592C >A (rs1800872) polimorfismo (3.259 casos e 4.992 controles), e três estudos para-819T >C (rs1800871) polimorfismo (477 casos e 544 controles). Ao reunir todos os estudos elegíveis, verificou-se que o Il-10-1082A $>$ G e-592C $>$ A polimorfismo não foram associados com o aumento do risco de câncer colorretal na população global. No entanto, houve associações significativas entre o polimorfismo IL-10-819T >C e a susceptibilidade de câncer colorretal o modelo alelo (A vs G: OR=1,278; 95\% CI 1,043-1,566; $P=0,018$ ) e o modelo recessivo (AA vs AG + GG: ou =1,709; 95\% CI 1,026-2,845; $P=0,039)$. Conclusão - Nesta meta-análise revelou-se que o polimorfismo IL-10-819T $>\mathrm{C}$ foi associado a um risco significativamente maior de câncer colorretal; enquanto o Il-10-1082A $>$ G e-592C $>$ A polimorfismos não foram associados com o risco de câncer colorretal. O polimorfismo IL-10-819T $>$ C pode ser importante como fator preditivo suspeito da ocorrência de câncer colorretal.

DESCRITORES - Interleucina-10. Neoplasias colorretais. Polimorfismo genético. Metanálise.

\section{REFERENCES}

1. Wang N, Wang L, Yang H, Zhang HQ, Lan B, He X, et al. Multiple genetic variants are associated with colorectal cancer risk in the Han Chinese population. Eur J Cancer Prev. 2014;1-5.

2. Forat-Yazdi M, Gholi-Nataj M, Neamatzadeh H, Nourbakhsh P, Shaker-Ardakani H. Association of XRCC1 Arg399Gln polymorphism with colorectal cancer risk: A huge meta-analysis of 35 studies. Asian Pacific J Cancer Prev. 2015;16:3285-91.

3. Khoram-Abadi KM, Forat-Yazdi M, Kheirandish S, Saeidi N, Zarezade Z, Mehrabi N, et al. DNMT3B -149 C $>$ T and -579 G>T Polymorphisms and Risk of Gastric and Colorectal Cancer: a Meta-analysis. Asian Pac J Cancer Prev. 2016;17:3015-20

4. Namazi A, Abedinzadeh M, Nourbaksh P, Neamatzadeh H. Association between the XRCC3 Thr241Met polymorphism and risk of colorectal cancer: A meta-analysis of 5,193 cases and 6,645 controls. Asian Pacific J Cancer Prev. 2015; $16: 2263-8$

5. Møller H, Sandin F, Robinson D, Bray F, Klint Å, Linklater KM, et al. Colorectal cancer survival in socioeconomic groups in England: Variation is mainly in the short term after diagnosis. Eur J Cancer. 2012;48:46-53.

6. Breen N, Lewis DR, Gibson JT, Yu M, Harper S. Assessing disparities in colorectal cancer mortality by socioeconomic status using new tools: health disparities calculator and socioeconomic quintiles. Cancer Causes Control. 2017;28:117-25.

7. Amersi F, Agustin M, Ko CY. Colorectal cancer: epidemiology, risk factors, and health services. Clin Colon Rectal Surg. 2005;18:133-40.

8. Haggar FA, Boushey RP. Colorectal cancer epidemiology: incidence, mortality, survival, and risk factors. Clin Colon Rectal Surg. 2009;22:191-7.

9. Pancione M, Remo A, Colantuoni V. Genetic and Epigenetic Events Generate Multiple Pathways in Colorectal Cancer Progression. Patholog Res Int 2012;2012:1-11.

10. Souglakos J. Genetic alterations in sporadic and hereditary colorectal cancer: implementations for screening and follow-up. Dig Dis. 2007;25:9-19.

11. Al-Sukhni W, Aronson M, Gallinger S. Hereditary Colorectal Cancer Syndromes: Familial Adenomatous Polyposis and Lynch Syndrome. Surg Clin North Am. 2008;88:819-44

12. Seruga B, Zhang H, Bernstein LJ, Tannock IF. Cytokines and their relationship to the symptoms and outcome of cancer. Nat Rev Cancer. 2008;8:887-99.

13. Sheikhpour E, Noorbakhsh P, Foroughi E, Farahnak S, Nasiri R, Neamatzadeh $\mathrm{H}$. A survey on the role of interleukin-10 in breast cancer: a narrative. Reports Biochem Mol Biol. 2018;7:30-7.

14. Namazi A, Forat-Yazdi M, Jafari M, Farahnak S, Nasiri R, Foroughi E, et al. Association of Interleukin-10 -1082 a/G (Rs1800896) Polymorphism With Susceptibility To Gastric Cancer: Meta-Analysis of 6,101 Cases and 8,557 Controls. Arq Gastroenterol. 2018;55:33-40.

15. Howell WM, Rose-Zerilli MJ. Cytokine Gene Polymorphisms, Cancer Susceptibility, and Prognosis. J Nutr. 2007;137:194S-199S
16. Yu Z, Liu Q, Huang C, Wu M, Li G. The Interleukin 10-819C/T Polymorphism and Cancer Risk: A HuGE Review and Meta-Analysis of 73 Studies Including 15,942 Cases and 22,336 Controls. Omi A J Integr Biol. 2013;17:200-14.

17. Zhang YM, Zhou XC, Xu Z, Tang CJ. Meta-analysis of epidemiological studies of association of two polymorphisms in the interleukin-10 gene promoter and colorectal cancer risk. Genet Mol Res. 2012 S;11:3389-97.

18. Mantel N, Haenszel W. Statistical aspects of the analysis of data from retrospective studies of disease. J Natl Cancer Inst. 1959;22:719-48.

19. DerSimonian R, Laird N. Meta-analysis in clinical trials. Control Clin Trials 1986; 7:177-88.

20. Begg CB, Mazumdar M. Operating characteristics of a rank correlation test for publication bias. Biometrics. 1994;50:1088-101.

21. Egger M, Davey Smith G, Schneider M, Minder C. Bias in meta-analysis detected by a simple, graphical test. BMJ. 1997;315:629-34.

22. Macarthur M, Sharp L, Hold GL, Little J, El-Omar EM. The Role of Cytokine Gene Polymorphisms in Colorectal Cancer and Their Interaction with Aspirin Use in the Northeast of Scotland. Cancer Epidemiol Biomarkers Prev. 2005;14:1613-8.

23. Crivello A, Giacalone A, Vaglica M, Scola L, Forte GI, Macaluso MC, et al Regulatory cytokine gene polymorphisms and risk of colorectal carcinoma. Ann N Y Acad Sci. 2006;1089:98-103.

24. Gunter MJ, Canzian F, Landi S, Chanock SJ, Sinha R, Rothman N. Inflammation-Related Gene Polymorphisms and Colorectal Adenoma. Cancer Epidemiol Biomarkers Prev. 2006;15:1126-31.

25. Cozar JM, Romero JM, Aptsiauri N, Vazquez F, Vilchez JR, Tallada M, et al High incidence of CTLA-4 AA (CT60) polymorphism in renal cell cancer. Hum Immunol. 2007;68:698-704.

26. Talseth BA, Meldrum C, Suchy J, Kurzawski G, Lubinski J, Scott RJ. Lack of association between genetic polymorphisms in cytokine genes and disease expression in patients with hereditary non-polyposis colorectal cancer. Scand J Gastroenterol. 2007;42:628-32.

27. Wilkening S, Tavelin B, Canzian F, Enquist K, Palmqvist R, Altieri A, et al. Interleukin promoter polymorphisms and prognosis in colorectal cancer. Carcinogenesis. 2008;29:1202-6.

28. Cacev T, Radosević S, Krizanac S, Kapitanović S. Influence of interleukin-8 and interleukin-10 on sporadic colon cancer development and progression. Carcinogenesis. 2008;29:1572-80.

29. Tsilidis KK, Helzlsouer KJ, Smith MW, Grinberg V, Hoffman-Bolton J, Clipp SL, et al. Association of common polymorphisms in IL10, and in other genes related to inflammatory response and obesity with colorectal cancer. Cancer Causes Control. 2009;20:1739-51.

30. Miteva LD, Stanilov NS, Deliysky TS, Stanilova SA. Significance of $-1082 \mathrm{~A} / \mathrm{G}$ polymorphism of IL10 gene for progression of colorectal cancer and IL-10 expression. Tumour Biol. 2014;35:12655-64.

31. Burada F, Dumitrescu T, Nicoli R, Ciurea ME, Rogoveanu I, Ioana M. Cytokine promoter polymorphisms and risk of colorectal cancer. Clin Lab. 2013;59:773-9. 
32. Basavaraju U, Shebl FM, Palmer AJ, Berry S, Hold GL, El-Omar EM, et al. Cytokine gene polymorphisms, cytokine levels and the risk of colorectal neoplasia in a screened population of Northeast Scotland. Eur J Cancer Prev. 2015;24: 296-304.

33. Li HX, Li YY, Song ZJ, He SX, Guo QY. Association between IL-8-251A/T and il-10-1082A/G genetic polymorphisms and susceptibility to colorectal cancer: A case-control study in a population in Shaanxi. World Chinese J Dig. 2015;23: 1184-90.

34. Cai J, Zhang Z. An Analysis of IL-10/IL-10R Genetic Factors Related to Risk of Colon Cancer and Inflammatory Bowel Disease in a Han Chinese Population. Clin Lab. 2016;62:1147-54.

35. Gulubova M, Aleksandrova E, Vlaykova T. Promoter polymorphisms in TGFB1 and IL10 genes influence tumor dendritic cells infiltration, development and prognosis of colorectal cancer. J Gene Med. 2018;e3005.

36. Vogel U, Christensen J, Dybdahl M, Friis S, Hansen RD, Wallin H, et al. Prospective study of interaction between alcohol, NSAID use and polymorphisms in genes involved in the inflammatory response in relation to risk of colorectal cancer. Mutat Res. 2007;624:88-100.

37. Andersen V, Egeberg R, Tjønneland A, Vogel U. Interaction between interleukin-10 (IL-10) polymorphisms and dietary fibre in relation to risk of colorectal cancer in a Danish case-cohort study. BMC Cancer. BioMed Central. 2012;12:183.
38. Yu Y, Zheng S, Zhang S, Jin W, Liu H, Jin M, et al. Polymorphisms of inflammation-related genes and colorectal cancer risk: a population-based case-control study in China. Int J Immunogenet. 2014;41:289-97.

39. Jafari Nedooshan J, Kargar S, Neamatzadeh H, Haghighi F, Dehghani Mohammad Abadi R, Seddighi N. Lack of Association of the Fat Mass and Obesity Associated (FTO) Gene rs9939609 Polymorphism with Breast Cancer Risk: a Systematic Review and Meta-Analysis Based on Case - Control Studies. Asian Pac J Cancer Prev. 2017;18:1031-7.

40. Jafari Nedooshan J, Forat Yazdi M, Neamatzadeh H, Zare Shehneh M, Kargar S, Seddighi N. Genetic Association of XRCC1 Gene rs1799782, rs25487 and rs25489 Polymorphisms with Risk of Thyroid Cancer: a Systematic Review and Meta-Analysis. Asian Pac J Cancer Prev. 2017;18:263-70.

41. Sadeghiyeh T, Hosseini Biouki F, Mazaheri M, Zare-Shehneh M, Neamatzadeh $\mathrm{H}$, Poursharif Z. Association between Catechol-O-Methyltransferase Val158Met (158G/A) Polymorphism and Suicide Susceptibility: A Meta-analysis. J Res Health Sci. 2017;17:e00383.

42. Mehdinejad M, Sobhan MR, Mazaheri M, Zare Shehneh M, Neamatzadeh H, Kalantar SM. Genetic Association between ERCC2, NBN, RAD51 Gene Variants and Osteosarcoma Risk: a Systematic Review and Meta-Analysis. Asian Pac J Cancer Prev. 2017;18:1315-21. 